\title{
Antileishmanial and Trypanocidal Activities of Extracts and Aporphine Alkaloids Isolated from Monodora Genus (Annonaceae)
}

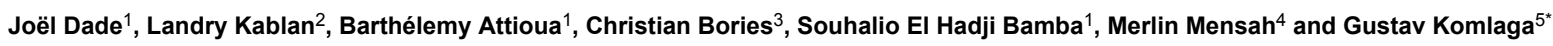 \\ ${ }^{1}$ Laboratoire de Chimie Organique et de Substances Naturelles, Université Félix Houphouët-Boigny, Abidjan, République de Côte d'Ivoire \\ 2UFR of Biological Sciences, Université Péléforo Gon Coulibaly, Korhogo, Côte d'lvoire \\ ${ }^{3}$ Department of Herbal Medicine, Kwame Nkrumah University of Science and Technology (KNUST), Kumasi, Ghana \\ ${ }^{4}$ Laboratory of Chemotherapy Antiparasitic, UMR BioCIS, Université Paris-Sud, Paris-Saclay University, Châtenay-Malabry, France \\ ${ }^{5}$ Department of Pharmacognosy, Kwame Nkrumah University of Science and Technology (KNUST), Kumasi, Ghana \\ *Corresponding author: Gustav Komlaga, Department of Pharmacognosy, Kwame Nkrumah University of Science and Technology, Kumasi, Ghana, Tel: \\ +233-322060366; E-mail: gustkomla@yahoo.com
}

Received date: Jul 10, 2017; Accepted date: Jul 28, 2017; Published date: Jul 31, 2017

Copyright: (c) 2017 Dade J, et al. This is an open-access article distributed under the terms of the Creative Commons Attribution License, which permits unrestricted use, distribution, and reproduction in any medium, provided the original author and source are credited.

\begin{tabular}{|c|}
\hline Abstract \\
\hline $\begin{array}{l}\text { Leishmaniasis and trypanosomiasis are protozoan diseases caused respectively by the kinetoplastid protozoan } \\
\text { Leishmania parasites transmitted by the female phlebotomine sandflies and Trypanosoma parasites transmitted by } \\
\text { the tsetse fly. In the search for agents from tropical medicinal plants to treat these two neglected tropical diseases, } \\
\text { serially extracted petroleum ether, dichloromethane and methanol extracts of the leaves of Monodora crispata and } \\
\text { Monodora brevipes, and eleven aporphines alkaloids isolated from the dried powdered leaves of the two plants were } \\
\text { evaluated against Leishmania donovani promastigotes and Trypanosoma brucei brucei trypomastigotes. The } \\
\text { extracts of both plants and the isolated compounds displayed varied levels of antiprotozoal activities. The } \\
\text { oxoaporphine compounds, }(+) \text {-anolobine }(7) \text { and }(+) \text {-listeferine }(8) \text {, exerted the most significant activity against } L \text {. } \\
\text { donovani ( }\left(\mathrm{I}_{50}: 14.59 \mu \mathrm{M}\right) \text { and } T \text {. brucei brucei }\left(\mathrm{LC}_{100}: 50.02 \mu \mathrm{M}\right) \text { respectively. This is the first report on the } \\
\text { antiprotozoal activity of the isolated compounds. The results offer potential for further studies of the oxoaporphines } \\
\text { for enhanced antiprotozoal activity. }\end{array}$ \\
\hline
\end{tabular}

Keywords: Antileishmanial; Trypanocidal; Monodora; Leishmania donovani; Trypanosoma brucei brucei; Aporphine alkaloids

\section{Introduction}

Leishmaniasis and trypanosomiasis are separate groups of arthropod-borne diseases of humans and other animals caused by infection with protozoan hemoflagellates of the genus Leishmania and Trypanosoma respectively. Both genera belong to the Trypanosomatidae family of the order Kinetoplastida [1]. These kinetoplastid diseases also referred to as Neglected Tropical Diseases (NTDs), are a diverse group of communicable diseases that prevail in tropical and subtropical conditions in 149 countries and affect more than one billion people, costing developing economies billions of dollars every year [2].

The genus Leishmania has more than 20 species. These are transmitted to humans by the bites of infected female phlebotomine sandflies which, breed in forest areas, caves, or the burrows of small rodents. There are three main forms of the disease: Cutaneous leishmaniasis which is the most common form of leishmaniasis and causes skin lesions, mainly ulcers, on exposed parts of the body, leaving life-long scars and serious disability; visceral leishmaniasis or kala-azar, which is fatal if left untreated in over $95 \%$ of cases and is characterized by irregular bouts of fever, weight loss, enlargement of the spleen and liver, and anaemia; and mucocutaneous leishmaniasis which leads to partial or total destruction of mucous membranes of the nose, mouth and throat [2]. According to WHO [2] an estimated 700,000 to 1 million new cases and 20,000 to 30,000 deaths occur annually.
Human African trypanosomiasis (HAT), also known as sleeping sickness is often fatal if left untreated [3]. The disease takes 2 forms, depending on the parasite involved: Trypanosoma brucei gambiense found in 24 countries in west and central Africa currently account for $97 \%$ of reported cases of sleeping sickness and causes chronic infection. The other, Trypanosoma brucei rhodesiense found in 13 countries in eastern and southern Africa represents fewer than $3 \%$ of reported cases. This causes acute infection. A third form known as American trypanosomiasis or Chagas disease occurs mainly in Latin America. The causal organism belongs to a different Trypanosoma subgenus and is transmitted by a different vector [4].

The drugs that are currently used for the treatment of these neglected tropical diseases suffer the limitations of toxicity, variable efficacy, requirements for parenteral administration and/or lengthy treatment regimen [3]. As a result, the search for new drug prototypes is an important requirement that needs to be pursued until the burden of these diseases can be reduced or eliminated. In the past few years, the interest in natural products as a potential source for the treatment of parasitic diseases has increased [5-8]. Traditionally, plants have been used for the treatment of protozoan diseases and phytotherapy has over the years received considerable attention in the search for alternative compounds with antiparasitic activity $[9,10]$. In our search for chemical agents from tropical medicinal plants for the treatment of Leishmaniasis and Trypanosomiasis, we evaluated eleven compounds, isolated from Monodora crispata and Monodora brevipes together with the serially extracted organic solvent extracts of the two plants against Leishmania donovani promastigotes and Trypanosoma brucei brucei trypomastigotes. 


\section{Materials and Methods}

\section{Plant materials}

Leaves of M. crispata and M. brevipes were collected in August 2010 in Diapodoumé (South of Côte d'Ivoire). They were authenticated by Aké Assi from the Centre National de Floristique (Université de Cocody-Abidjan). Herbarium specimens were deposited at the Herbarium of the Laboratoire de Botanique (Université de CocodyAbidjan), with the voucher numbers: MC-DADE-Diapodoumé2010-1 and MB-DADEDiapodoumé2010-1 respectively.

\section{Extraction of plant materials}

Dried powdered leaves of $M$. crispata and M. brevipes were each serially cold-extracted with petroleum ether, dichloromethane and methanol. The extracts were each concentrated under reduced pressure using the rotavapor at $40^{\circ} \mathrm{C}$ into semisolid mass. The semisolid mass was further dried under vacuum to give a hardened amorphous mass, which was kept in the fridge until needed for use.

\section{Isolated compounds}

Eleven aporphines alkaloids (Figure 1) identified as, (-)mocrispatine (1); (-)-pallidine (2); (-) N-méthylarmépavine (3); (+)magnoflorine (4); (+)-menispermine (5); (-)-anolobine (6); (+)anolobine (7); (+)-listeferine (8); (+)-réoméroline (9); (+)laurotetanine (10) and (+)-corydine (11) isolated from the dried powdered leaves of M. crispata and brevipes $[11,12]$ were used in this study.

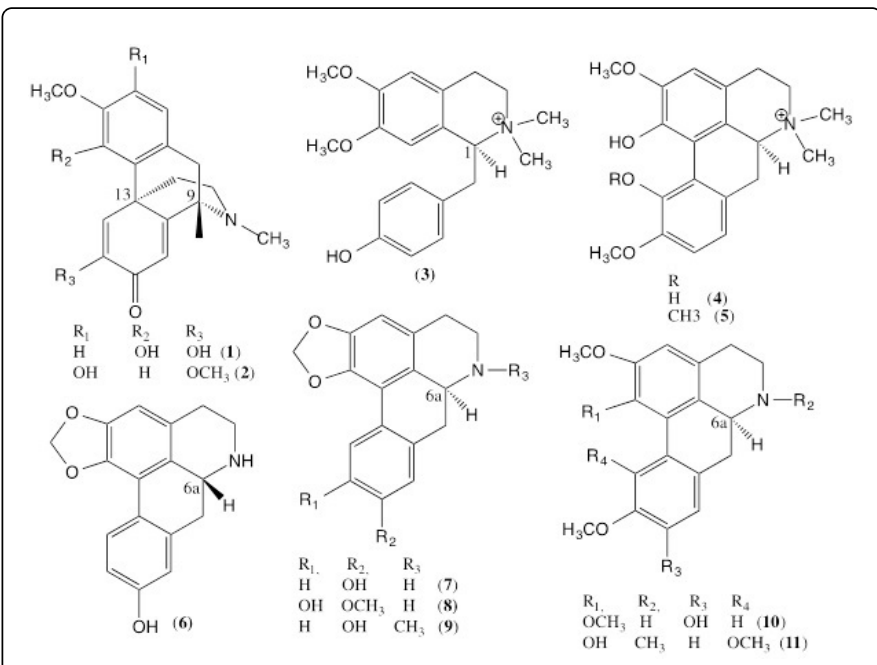

Figure 1: Aporphine alkaloids isolated from M. crispata and $M$. brevipes.

\section{Determination of antileishmanial activity of test samples}

The antileishmanial activity of the isolated compounds was tested in vitro against L. donovani (WHO designation: MHOM/ET/1967/L82), according to a method previously described [13]. This method is based on a dye, tetrazolium-dye, specific for dead parasites, thus allowing the measurement of an $\mathrm{EC}_{50}$ value. Briefly, promastigotes were cultivated in HEPES (25 mm)-buffered RPMI 1640 medium enriched with $10 \%$ fetal calf serum and $50 \mu \mathrm{g} / \mathrm{mL}$ gentamicin at $27^{\circ} \mathrm{C}$ in a dark environment. The screening was performed in flat bottomed 96-well plastic tissue-culture plates maintained at $27^{\circ} \mathrm{C}$. Promastigotes forms from a logarithmic phase culture were suspended to yield about 106 cells $/ \mathrm{mL}$ after haemocytometer counting. Each well was filled with 100 $\mu \mathrm{l}$ of the parasite suspension, and the plates were incubated at $27^{\circ} \mathrm{C}$ for $1 \mathrm{~h}$ before the addition of the samples, dissolved in Dimethyl Sulfoxide (DMSO) at different concentrations up to $100 \mu \mathrm{g} / \mathrm{ml}$ for both extracts and compounds. The viability of promastigotes was assessed by the Tetrazolium-dye (MTT) colorimetric method. The results are expressed as the effective concentrations $\left(\mathrm{IC}_{50}\right)$ inhibiting parasite growth by $50 \%$ after a 3 -day incubation period. Pentamidine and was used as reference compound. Experiments were performed in triplicate. A maximum DMSO concentration of $0.1 \%$, which did not show toxicity, was used in the final well volume of $200 \mathrm{ml}$.

\section{Determination of trypanocidal activity of test samples}

Compounds were tested for their activity against bloodstream forms of T. brucei brucei (CMP fast strain) as described elsewhere [14,15]. This method was based on the observation of the motility of cultivated parasites, followed by the inoculation to naive mice of the solution of immobile parasites with the $\mathrm{LC}_{100}$ of the tested compound. No infection confirms the trypanocidal effect for $\mathrm{LC}_{100}$. Briefly, the bloodstream parasites were maintained in vitro without loss of infectivity for $24 \mathrm{~h}$ in the dark at $37^{\circ} \mathrm{C}$ in a $5 \% \mathrm{CO}_{2}$ atmosphere. Screening was performed in 96-well tissue-culture plate in a final well volume of $200 \mathrm{ml}$ containing $2 \times 10^{5}$ parasites $/ \mathrm{ml}$, in supplemented minimum essential medium (Gibco, BRL). Samples were tested at varied concentrations up to $100 \mu \mathrm{g} / \mathrm{ml}$ for both extracts and compounds (diluted in DMSO) and the minimum lethal concentration $\left(\mathrm{LC}_{100}\right.$ : defined as the minimum concentration at which no motile parasites were observed microscopically) determined. Confirmation of the $\mathrm{LC}_{100}$ was obtained by injecting naive mice intraperitoneally with $150 \mu \mathrm{l}$ of the treated trypanosome suspension withdrawn from the well after a $24 \mathrm{~h}$ incubation period. The animals were aparasitaemic 30 days post-infection. Melarsoprol and pentamidine were used as reference compounds. Experiments were performed in triplicate. A maximum DMSO concentration of $0.1 \%$ which did not show toxicity was used in the final well volume.

\section{Results and Discussion}

Methanol, dichloromethane and petroleum ether extracts of $M$. brevipes and M. crispata showed various levels of antiprotozoal activity against $L$. donovani promastigotes and $T$. brucei brucei trypomastigotes in Table 1 . The extracts were more active against $L$. donovani than $T$. brucei brucei; while all were active against $L$. donovani $\left(\mathrm{EC}_{50}<100 \mu \mathrm{g} / \mathrm{mL}\right.$ ), only three including the methanol extract of $M$. brevipes, dichloromethane and petroleum extracts of $M$. crispata, showed activity against $T$. brucei brucei $\left(\mathrm{CL}_{100}<100 \mu \mathrm{g} / \mathrm{mL}\right)$. $M$. crispata extracts were generally the most active; the dichloromethane and methanol extracts were respectively the most active against $L$. donovani and T. brucei brucei.

The eleven aporphine alkaloids; two promorphinanes: [(-)mocrispatine (1), (-)-pallidine (2)], one benzylisoquinoline: [(-)-Nmethylarmepavine (3)], four aporphines: $[(+)$-magnoflorine $(4),(+)-$ ménispermine (5), (+)-laurotetanine (10) and $(+)$-corydine (11)], and four oxoaporphines [(-)-anolobine (6); (+)-anolobine (7); (+)listeferine (8); (+)-roemeroline (9)] have shown varied levels of antiprotozoal activity against $L$. donovani promastigotes and T. brucei brucei trypomastigotes in Table 2. 
Page 3 of 4

\begin{tabular}{|l|l|l|}
\hline Extracts & $\begin{array}{l}\text { Leishmania } \\
\text { donovani }\end{array}$ & $\begin{array}{l}\text { Trypanosoma } \\
\text { brucei brucei }\end{array}$ \\
\hline Concentration & $\mathrm{IC}_{50}(\mathrm{\mu g} / \mathrm{mL})$ & $\mathrm{CL}_{100}(\mathrm{\mu g} / \mathrm{mL})$ \\
\hline Monodora brevipes methanol extract & 64.2 & 50.0 \\
\hline $\begin{array}{l}\text { Monodora brevipes dichloromethane } \\
\text { extract }\end{array}$ & 56.5 & $>100$ \\
\hline $\begin{array}{l}\text { Monodora brevipes petroleum ether } \\
\text { extract }\end{array}$ & 60.7 & $>100$ \\
\hline $\begin{array}{l}\text { Monodora crispata methanol extract } \\
\text { Monodora crispata dichloromethane } \\
\text { extract }\end{array}$ & 33.9 & 10.8 \\
\hline Monodora crispata petroleum ether extract & 16.6 & 31.3 \\
\hline Pentamidine & 2.6 & - \\
\hline Mélarsoprol (Mel W) & - & 0.2 \\
\hline
\end{tabular}

Table 1: Antiprotozoal activity of extracts of Monodora genus (leaves).

\begin{tabular}{|l|l|l|}
\hline Compound & $\begin{array}{l}\text { Leishmania } \\
\text { donovani }\end{array}$ & $\begin{array}{l}\text { Trypanosoma brucei } \\
\text { brucei }\end{array}$ \\
\hline Concentration & $\mathrm{EC}_{50}(\mu \mathrm{m})$ & $\mathrm{LC}_{100}(\mu \mathrm{m})$ \\
\hline (-)-mocrispatine (1) & 193.93 & 199.68 \\
\hline (-)-pallidine (2) & 53.82 & 191.13 \\
\hline (-) N-méthylarmépavine (3) & $>200$ & $>200$ \\
\hline$(+)$-magnoflorine (4) & $>200$ & $>200$ \\
\hline (+)-ménispérmine (5) & $>200$ & $>200$ \\
\hline (-)-anolobine (6) & 19.21 & 114.95 \\
\hline (+)-anolobine (7) & 14.59 & $>200$ \\
\hline (+)-listeferine (8) & 26.69 & 50.02 \\
\hline$(+)$-réoméroline (9) & 52.20 & $>200$ \\
\hline (+)-laurotetanine (10) & 23.24 & 191.13 \\
\hline (+)-corydine (11) & 174.78 & 183.28 \\
\hline Pentamidine & 7.7 & - \\
\hline Mélarsoprol (Mel W) & - & 0.4 \\
\hline & & \\
\hline
\end{tabular}

Table 2: Antiprotozoal activity of isolated compounds.

The compounds in a manner similar to the extracts were largely more active against $L$. donovani promastigotes. The oxoaporphines were generally the most active especially against $L$. donovani $(14.59 \leq$ $\left.\mathrm{IC}_{50} \geq 52.20 \mu \mathrm{m}\right)$. The aporphine, (+)-laurotetanine (10), also showed good activity against $L$. donovani $\left(\mathrm{IC}_{50}=23.24 \mu \mathrm{m}\right)$. The oxoaporphine alkaloid, (+)-listeferine (8) was the most active compound against $T$. brucei brucei with an $\mathrm{LC}_{100}$ value of $50.02 \mu \mathrm{m}$. Two such alkaloides, $(+)$-reomeroline (9) and (+)-anolobine (7) nevertheless did not show activity against $T$. brucei brucei. Interestingly however, (+)-anolobine (7) was the most active against $L$. donovani $\left(\mathrm{IC}_{50}=14.59 \mu \mathrm{m}\right)$ and has $\mathrm{IC}_{50}$ value of about twice that of the standard drug, Pentamidine
$\left(\mathrm{IC}_{50}=7.7 \mu \mathrm{m}\right)$. Its $\mathrm{IC}_{50}$ value also falls within the range given for the putative antileishmania drug, sitamaquine $\left(2.9 \geq \mathrm{IC}_{50} \leq 19.0 \mu \mathrm{m}\right)$ [8]. 7 is therefore a potential candidate for further studies as an antileishmanial compound. (+)-Listeferine (8), the most active compound against $T$. brucei brucei, on the other hand, was 125 fold less active than the reference drug, Mélarsoprol. Three compounds exhibited no activity against either parasite.

The generally low antiprotozoal activity of the aporphines does not make them good candidates for either leishmaniasis or trypanosomiasis therapy. However, the activity demonstrated by the oxoaporphines tells of their potential as important class of phytochemicals that could be a subject of activity optimization through structural modification. Indeed, some of the oxoaporphines which differ slightly in chemical structure showed clear differences in activity in this study. For example, $(+)$-Listeferine (8; Figure 1 ) which is a demethylated derivative of $(+)$-reomeroline (9), is about twice more active than the latter against $L$. donovani; an observation that demethylation at $\mathrm{R}_{3}$ led to increased antiprotozoal activity of the latter.

Members of the Annonaceae family and their isolated compounds have demonstrated antiprotozoal activities including antiplasmodial, leishmanicidal and antitrypanosomal activities [6,7]. Literature data also revealed similar activity of the related aporphines. Oxoaporphines closely related to those evaluated in this study particularly possess promising antiprotozoal activity especially antitrypanosomal activities [5]. It is therefore not surprising that the oxoaporphines are the most active molecules in this study. This is the first report of the antiprotozoan activity of $M$. crispat, $M$. brevipes and the isolated compounds, and it portrays the oxoaporphine as potential candidates for further structural modification-activity study.

\section{Conclusion}

The organic solvent extracts of $M$. crispat, $M$. brevipes and their isolated aporphines showed varied levels of activity against $L$. donovani promastigotes than T. brucei brucei trypomastigotes. The oxoaporphines were particularly active especially against $L$. donovani and therefore are potential candidates for further studies for enhancement of their antileishmanaial activity.

\section{Acknowledgement}

The authors are grateful to late Prof. Aké Assi, Botanical Department of University of Cocody-Abidjan, for identifying the plant material. Thanks also the Ministry of Research of the République de Côte d'Ivoire for the financial support.

\section{Ethical Approval}

All applicable international, national, and institutional guidelines for the care and use of animals were followed.

\section{References}

1. Eldridge P, Edman JD (2004) Medical entomology. A Textbook on Public Health and Veterinary Problems Caused by Arthropods (Revised Edn.). Springer Science+Business Media, BV.

2. The World Health Organization (WHO) (2017) Leishmaniasis fact sheet. WHO Press.

3. Barrett MP, Croft SL (2012) Management of trypanosomiasis and leishmaniasis. British Medical Bulletin, Oxford University Press. 
Citation: Dade J, Kablan L, Attioua B, Bories C, El Hadji Bamba S, et al. (2017) Antileishmanial and Trypanocidal Activities of Extracts and Aporphine Alkaloids Isolated from Monodora Genus (Annonaceae). J Pharmacogn Nat Prod 3: 136. doi:10.4172/2472-0992.1000136

Page 4 of 4

4. The World Health Organization (WHO) (2017) Trypanosomiasis, human African fact sheet. WHO Press.

5. Hoet S, Stévigny C, Block S, Opperdoes F, Colson P, et al. (2004) Alkaloids from Cassytha filiformis and related aporphines: Antitrypanosomal activity, cytotoxicity, and interaction with DNA and topoisomerases. Planta Medica 70: 407-413.

6. Waechter AI, Cavé A, Hocquemiller R, Bories C, Muñoz V, et al. (1999) Antiprotozoal activity of aporphine alkaloids isolated from Unonopsis buchtienii (Annonaceae). Phytother Res 13: 175-177.

7. Malebo HM, Wenzler T, Cal M, Swaleh SM, Omolo MO, et al. (2013) Anti-protozoal activity of aporphine and protoberberine alkaloids from Annickia kummeriae (Engl. \& Diels) Setten \& Maas (Annonaceae). BMC Complement Altern Med 13: 48.

8. Loiseau PM, Cojean S, Schrével J (2011) Sitamaquine as a putative antileishmanial drug candidate: from the mechanism of action to the risk of drug resistance. Parasite (Paris, France) 18: 115-119.

9. Neves-Pinto C, Malta VRS, Pinto Mdo CFR, Santos RHA, de Castro SL, et al. (2002) A trypanocidal phenazine derived from $\beta$-lapachone. J Med Chem 45: 2112-2115.
10. Muelas-Serrano S, Nogal-Ruiz JJ, Gómez-Barrio A (2000) Setting of a colorimetric method to determine the viability of Trypanosoma cruzi epimastigotes. Parasitol Res 86: 999-1002.

11. Kablan L, Dade J, Okpekon T, Roblot F, Djakouré LA, et al. (2013) Alkaloids from the leaves of Monodora crispata Engl. and Diels and $M$. brevipes Benth. (Annonaceae). Biochem Syst Ecol 46: 162-165.

12. Kablan L (2014) Etudes chimique et biologique de plantes issues de la flore de Côte d'Ivoire: Monodora brevipes Benth., Monodora crispata Eng. et Diels (Annonaceae), Erythrophleum suaveolens (Guill. et Perr.) Brenan (Fabaceae) et Sacoglottis gabonensis Urb. (Humiriac).

13. Mbongo N, Loiseau PM, Lawrence F, Bories C, Craciunescu DG, et al. (1997) In vitro sensitivity of Leishmania donovani to organometallic derivatives of pentamidine. Parasitol Res 83: 515-517.

14. Loiseau PM, Lubert P, Wolf JG (2000) Contribution of dithiol ligands to in vitro and in vivo trypanocidal activities of dithiaarsanes and investigation of ligand exchange in an aqueous solution. Antimicrob Agents Chemother 44: 2954-2961.

15. Pomel S, Biot C, Bories C, Loiseau PM (2013) Antiprotozoal activity of ferroquine. Parasitol Res 112: 665-669. 